\title{
Design of Medical Devices Using Spongy Sheet Composed of Hyaluronic Acid and Collagen
}

\author{
Yoshimitsu Kuroyanagi ${ }^{1,2 *}$, Haruka Ohno', Ryusuke Suzuki3 \\ Misato Kuroyanagi ${ }^{4}$, Ichiro Takeuchi ${ }^{4}$ \\ ${ }^{1} \mathrm{R} \&$ D Center for Skin Regenerative Medicine, Technosurg Ltd., Sagamihara, Japan \\ ${ }^{2}$ School of Allied Health Sciences, Kitasato University, Sagamihara, Japan \\ ${ }^{3}$ New Business Development Division, Mitsui Fine Chemicals, Inc., Tokyo, Japan \\ ${ }^{4}$ Department of Emergency Medicine, Yokohama City University Graduate School of Medicine, Yokohama, Japan \\ Email: ^drs.yoshi@technosurg.co.jp
}

How to cite this paper: Kuroyanagi, Y. Ohno, H., Suzuki, R., Kuroyanagi, M. and Takeuchi, I. (2020) Design of Medical Devices Using Spongy Sheet Composed of Hyaluronic Acid and Collagen. Open Journal of Regenerative Medicine, 9, 71-84.

https://doi.org/10.4236/ojrm.2020.92008

Received: May 1, 2020

Accepted: May 26, 2020

Published: May 29, 2020

Copyright (C) 2020 by author(s) and Scientific Research Publishing Inc. This work is licensed under the Creative Commons Attribution International License (CC BY 4.0).

http://creativecommons.org/licenses/by/4.0/

\section{Abstract}

This research aims to obtain useful information for development of medical devices such as wound dressing and tissue anti-adhesive product, using a spongy sheet composed of hyaluronic acid (HA) and collagen (Col). The spongy sheets were manufactured by freeze vacuum drying of $\mathrm{HA}$ and $\mathrm{Col}$ aqueous solution, followed by UV irradiation to introduce intermolecular crosslinks between Col molecules. These spongy sheets are referred to as Sponge-A (ratio of $\mathrm{HA} / \mathrm{Col}=5 / 1$ ) and Sponge-B (ratio of $\mathrm{HA} / \mathrm{Col}=5 / 5$ ). Both surfaces of Sponge-A and Sponge-B treated with UV irradiation for 15 minutes are referred to as Sponge-A-15 and Sponge-B-15, respectively. The weight change of spongy sheet was determined by immersing a peace of spongy sheet in water at $37^{\circ} \mathrm{C}$. The weight of sponge-A-15 collected $1 / 2,1,3,7$ days after immersion in water was $63.5 \%, 62.1 \%, 56.6 \%, 54.4 \%$ of the original weight, respectively. The weight of Sponge-B-15 was $78.3 \%, 76.7 \%, 79.1 \%$, $71.9 \%$ of the original weight, respectively. The weight change of spongy sheet was determined by immersing a peace of spongy sheet in water containing collagenase at $37^{\circ} \mathrm{C}$. The weight of Sponge-A-15 collected 6, 8, 10, 12 hours after immersion in water containing collagenase $(0.0005 \mathrm{w} / \mathrm{v} \%)$ was $65.7 \%$, $59.8 \%, 57.9 \%, 55.2 \%$ of the original weight, respectively. The weight of Sponge-B-15 was $63.5 \%, 52.1 \%, 42.0 \%, 43.2 \%$ of the original weight, respectively. This spongy sheet is considered to have the unique structure, where HA molecules are entrapped in an intermolecular cross-linked network structure of Col molecules. When immersed in water containing collagenase, the weight loss of spongy sheet is accelerated by easy extraction of HA molecules from the enzymatic degraded Col network structure. The performance of wound dressing and tissue anti-adhesive product is considered to depend on appro- 
priate ratio of $\mathrm{HA}$ and $\mathrm{Col}$, and also on appropriate rate of intermolecular crosslinks between Col molecules. These findings obtained in this study provide useful information for product development such as wound dressing and tissue anti-adhesive product.

\section{Keywords}

Hyaluronic Acid, Collagen, Wound Dressing, Tissue Non-Adhesive Product, Intermolecular Crosslinks

\section{Introduction}

The practical design of medical devices such as wound dressing and tissue anti-adhesive product is found by understanding the general wound healing process. Wound dressings are applied to external wounds, while tissue anti-adhesive products are applied to internal wounds. However, both medical devices should be designed to have a common function that facilitates the wound healing process [1] [2] [3] [4]. The wound dressings need to facilitate the healing process under the impaired conditions such as burn injury and intractable skin ulcer. In case of tissue anti-adhesive products, two events need to proceed simultaneously. One is to promote wound healing of surgically resected tissue surface. Another is to prevent surgically resected tissue surface from adhering to the surrounding tissue surface. The superior performance of wound dressing and tissue anti-adhesive product depends on the properties of the material itself. HA is identified as a major extracellular component. Because of its unique hygroscopic, rheological and viscoelastic properties, HA creates an excellent wound healing environment. HA is an important biomaterial for wound healing as it has various biological activities [5] [6]. Col is a primary connective tissue component, providing strength and integrity to all tissues. Col is also an important biomaterial for wound healing as it has various biological activities [7]. Based on such a concept, various types of wound dressings and tissue anti-adhesive products have been developed by using HA and Col [8] [9] [10] [11]. The spongy sheet composed of HA and Col is dissolve in water. Therefore, the intermolecular crosslinks of this spongy sheet need to be controlled to provide superior performance as medical devices. The purpose of this study is to provide useful information in developing medical devices such as wound dressing and tissue anti-adhesive product, using a spongy sheet composed of HA and Col.

\section{Materials and Methods}

\subsection{Manufacture of Spongy Sheet Composed of HA and Col}

HA powder (Bio Sodium Hyaluronate HA 20, molecular weight; $2000 \mathrm{kDa}$ ) was purchased from Shiseido (Tokyo, Japan). Col power derived from porcine skin was purchased from Nippon Meat Packers (Osaka, Japan). HA powder (30 g) 
was dissolved in distilled water (DW) $(2000 \mathrm{~mL})$ under stirring using a $15 \mathrm{~cm}$ diameter screw propeller at a speed of 1 revolution per second at $20^{\circ} \mathrm{C}$ overnight to obtain HA aqueous solution ( $\mathrm{pH} 6.8$ ). Col power (6 g) was dissolved in DW $(400 \mathrm{~mL})$ under stirring using a $9 \mathrm{~cm}$ screw propeller at a speed of 2 revolutions per second at $20^{\circ} \mathrm{C}$ overnight, and then warmed at $60^{\circ} \mathrm{C}$ for 60 minutes to obtain Col aqueous solution ( $\mathrm{pH}$ 2.8). This Col aqueous solution is referred to as heat-denatured $\mathrm{Col}$ aqueous solution. This $\mathrm{Col}$ aqueous solution was mixed with $\mathrm{HA}$ aqueous solution by stirring and then adjusted to neutral conditions ( $\mathrm{pH} 7.0$ - 7.2) by dropping $\mathrm{NaOH}$ aqueous solution. This mixture $(60 \mathrm{~mL})$ was poured into a plastic tray $(10 \mathrm{~cm} \times 12 \mathrm{~cm})$ and refrigerated at $4^{\circ} \mathrm{C}$ for 6 hours, and then was frozen at $-85^{\circ} \mathrm{C}$ overnight, followed by freeze vacuum drying to obtain a spongy sheet. This spongy sheet is referred to as Sponge-A (ratio of HA/Col = $5 / 1)$. In a similar manner, another spongy sheet was manufactured. HA powder $(18 \mathrm{~g})$ was dissolved in DW $(1200 \mathrm{~mL})$. Col powder $(18 \mathrm{~g})$ was dissolved in DW $(1200 \mathrm{~mL})$. The spongy sheet was manufactured using the mixture of both solutions. This spongy sheet is referred to as Sponge-B (ratio of $\mathrm{HA} / \mathrm{Col}=5 / 5$ ). Both sides of the spongy sheet were irradiated using a $15 \mathrm{~W}$ ultraviolet lamp with a wavelength of $253.7 \mathrm{~nm}$ at a distance of $20 \mathrm{~cm}$ to introduce intermolecular crosslinks between Col molecules. Sponge-A treated with UV irradiation for 5, 10, 15 minutes is referred to as Sponge-A-5, Sponge-A-10, Sponge-A-15, respectively. Sponge-B treated with UV irradiation for 5, 10, 15 minutes is referred to as Sponge-B-5, Sponge-B-10, Sponge-B-15, respectively. This spongy sheet was cut to a size of $3.5 \mathrm{~cm} \times 5.5 \mathrm{~cm}$ for use in immersion tests.

\subsection{Weight and Size Change of Spongy Sheet after Immersion in Water}

The weight change of spongy sheet was determined by immersing a peace of spongy sheet (size: $3.5 \mathrm{~cm} \times 5.5 \mathrm{~cm}$, weight: $0.2 \mathrm{~g}$ ) in a container filled with DW $(200 \mathrm{~mL})$ at $37^{\circ} \mathrm{C}$. The hydrated spongy sheet collected $1 / 2,1,3,7$ days after immersion in water was frozen at $-85^{\circ} \mathrm{C}$ overnight, followed by freeze vacuum drying to obtain a spongy sheet. The weight of each spongy sheet was measured and compared with its original weight. In addition, the size of each spongy sheet was calculated and compared with its original size. The outline of each spongy sheet was traced on a clear plastic film, and then the weight of cut film was converted to size using the correlation measurements of the film weight and size.

\subsection{Enzymatic Degradation of Spongy Sheet by Collagenase}

Collagenase $(0.008 \mathrm{~g}$ or $0.016 \mathrm{~g})$ was dissolved in DW $(1600 \mathrm{~mL})$, and then this solution $(200 \mathrm{~mL})$ was poured in eight containers. The enzyme concentration was adjusted to $0.0005 \%(\mathrm{w} / \mathrm{v})$ and $0.001 \%(\mathrm{w} / \mathrm{v})$. The weight change of spongy sheet was determined by immersing a peace of Sponge-A-15 or Sponge-B-15 (size: $3.5 \mathrm{~cm} \times 5.5 \mathrm{~cm}$, weight: $0.2 \mathrm{~g}$ ) in a container filled with DW $(200 \mathrm{~mL})$ containing collagenase at $37^{\circ} \mathrm{C}$. The hydrated spongy sheet collected $6,8,10,12$ 
hours after immersion in water was frozen at $-85^{\circ} \mathrm{C}$ overnight, followed by freeze vacuum drying to obtain a spongy sheet. The weight of each spongy sheet was measured and compared with its original weight.

\subsection{Statistical Evaluation}

Data are expressed as means \pm standard error (SE). Statistical analysis was performed using Student's t-test for comparison between two groups. Each experiment was conducted 8 times and evaluated $(n=8)$.

\section{Result}

\subsection{Manufacture of Spongy Sheet Composed of HA and Col}

Prior to manufacturing spongy sheet, the characteristics of Col aqueous solution were examined. The Col concentration was adjusted to $1.5 \%(\mathrm{w} / \mathrm{v})$. The viscosity of $\mathrm{Col}$ aqueous solution was measured at the range from $20^{\circ} \mathrm{C}$ to $60^{\circ} \mathrm{C}$ using a standard viscometer. This viscometer rotates the cylindrical part in the solution and measures the rotating top surface resistance at each temperature. The viscosity was $19.3,17.2,13.3,4.2$, less than 0.1 , less than $0.1 \mathrm{dPa} \cdot \mathrm{s}$ at $20^{\circ} \mathrm{C}, 25^{\circ} \mathrm{C}$, $30^{\circ} \mathrm{C}, 35^{\circ} \mathrm{C}, 40^{\circ} \mathrm{C}, 60^{\circ} \mathrm{C}$, respectively. The $\mathrm{Col}$ aqueous solution was warmed at $60^{\circ} \mathrm{C}$, and then cooled to $20^{\circ} \mathrm{C}$. Under these conditions, the viscosity at $20^{\circ} \mathrm{C}$ was $0.4 \mathrm{dPa} \cdot \mathrm{s}$. This heat-denatured $\mathrm{Col}$ aqueous solution does not cause precipitation even at neutral conditions ( $\mathrm{pH} 7.0$ - 7.2). The heat-denatured Col aqueous solution can be mixed with HA aqueous solution without causing any precipitation. This mixture was adjusted to neutral conditions at $20^{\circ} \mathrm{C}$. The spongy sheet was manufactured by freeze vacuum drying this clear mixed solution. The both side of spongy sheet was irradiated by UV lamp to introduce intermolecular crosslinks between Col molecules. The spongy sheet slightly turns yellow when UV irradiation period is more than 10 minutes.

In this study, two types of spongy sheets were manufactured. One is Sponge-A (ratio of $\mathrm{HA} / \mathrm{Col}=5 / 1)$. Another is Sponge-B (ratio of $\mathrm{HA} / \mathrm{Col}=5 / 5)$. In a preliminary experiment, other types of spongy sheets were manufactured. The spongy sheet (ratio of $\mathrm{HA} / \mathrm{Col}=10 / 1$ ) failed to collect after immersion in water, because of inadequate intermolecular crosslinks between Col molecules. Therefore, Sponge-A was chosen as a product with the lowest Col content. On the other hand, the spongy sheet (ratio of $\mathrm{HA} / \mathrm{Col}=2 / 5$ ) is not soft. Therefore, Sponge-B was chosen as a product with the appropriate softness. This study can provide useful information in production of spongy sheet having appropriate softness and appropriate intermolecular crosslinks between Col molecules. According to this information, other spongy sheet having appropriate ratio of HA/Co ranged from $5 / 1$ to $5 / 5$ can be manufactured responding to clinical requirements. In addition, the concentration of $\mathrm{HA}$ and $\mathrm{Col}$ aqueous solution was chosen at $1.5 \mathrm{w} / \mathrm{v} \%$ to obtain spongy sheet having appropriate softness. When the concentration of HA and Col aqueous solution is $1.0 \mathrm{w} / \mathrm{v} \%$, the manufactured spongy sheet is too soft. This spongy sheet is not suitable for operability in clinical use. 


\subsection{Weight and Size Change of Spongy Sheet after Immersion in Water}

The weight change of Sponge-A or Sponge-B was measured 1/2, 1, 3, 7 days after immersion in water at $37^{\circ} \mathrm{C}$. The weight of Sponge-A-5 was $59.1 \%, 56.2 \%$, $47.2 \%, 46.2 \%$ of the original weight, respectively. The weight of Sponge-B-5 was $73.6 \%, 68.6 \%, 56.5 \%, 58.5 \%$ of the original weight, respectively (Figure 1 ). The weight of Sponge-A-10 was $61.3 \%, 57.2 \%, 53.0 \%, 54.7 \%$ of the original weight, respectively. The weight of Sponge-B-10 was $75.2 \%, 76.8 \%, 72.8 \%, 68.2 \%$ of the original weight, respectively (Figure 2). The weight of Sponge-A-15 was 63.5\%, 62.1\%,

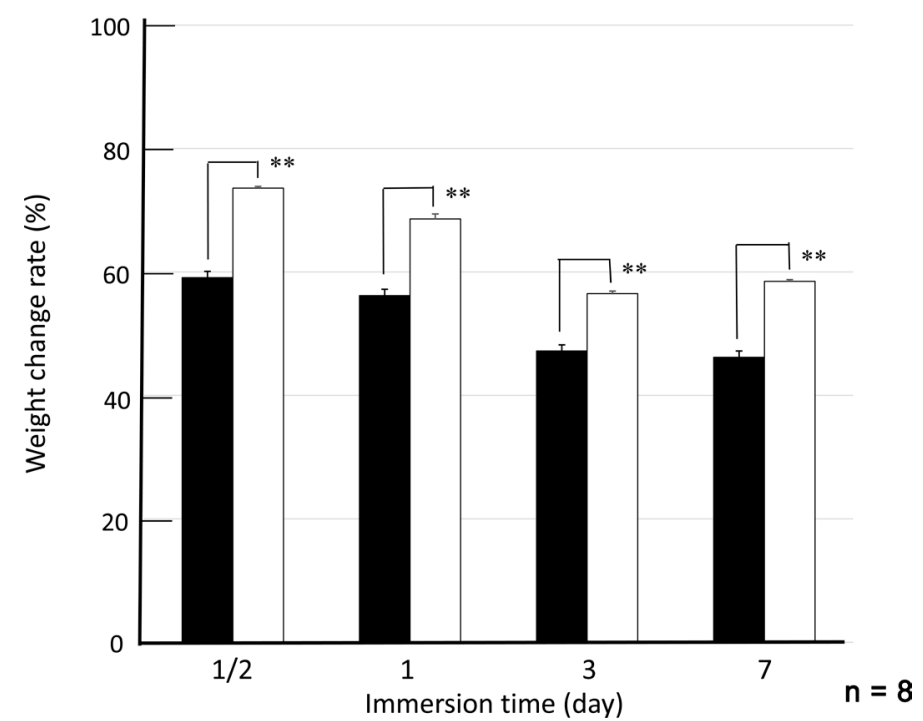

${ }^{*} \mathrm{P}<0.01$ vs. Sponge-A-5 [Student's t-test]

Figure 1. Weight change rate of Sponge-A-5 and Sponge-B-5 after immersion in water: (ם) Sponge-A-5, ( $\square$ ) Sponge-B-5.

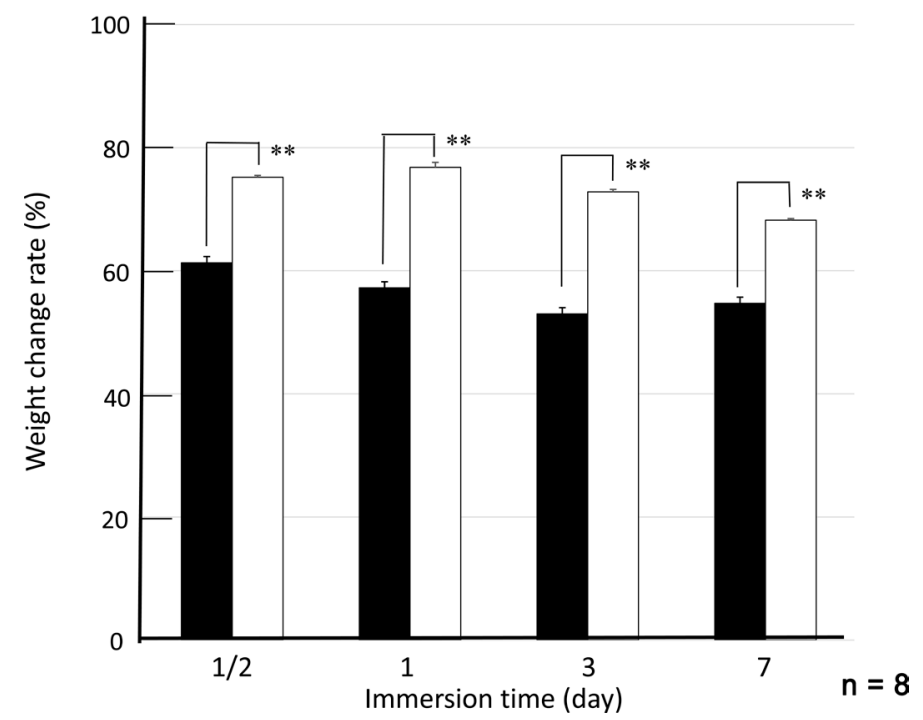

${ }^{*} \mathrm{P}<0.01$ vs. Sponge-A-10 [Student's t-test].

Figure 2. Weight change rate of Sponge-A-10 and Sponge-B-10 after immersion in water: ( $\square)$ Sponge-A-10, ( $\square$ ) Sponge-B-10. 
$56.6 \%, 54.4 \%$ of the original weight, respectively. The weight of Sponge-B-15 was $78.3 \%, 76.7 \%, 79.1 \%, 71.9 \%$ of the original weight, respectively (Figure 3 ). There is no statistical difference among four data, 78.3\%, 76.7\%, 79.1\%, and $71.9 \%$. The findings shown in Figure 3 indicate that Sponge-B-15 having the highest intermolecular crosslinks rate can control the decrease in weight within about $72 \%$ of the original weight for 7 days immersion in water.

The size change of Sponge-A or Sponge-B was measured 1/2, 1, 3, 7 days after immersion in water at $37^{\circ} \mathrm{C}$. The size of Sponge-A-5 was $194 \%, 218 \%, 239 \%$, $238 \%$ of the original size, respectively. The size of Sponge-B-5 was $142 \%, 181 \%$, $223 \%, 207 \%$ of the original size, respectively (Figure 4). The size of Sponge-A-10

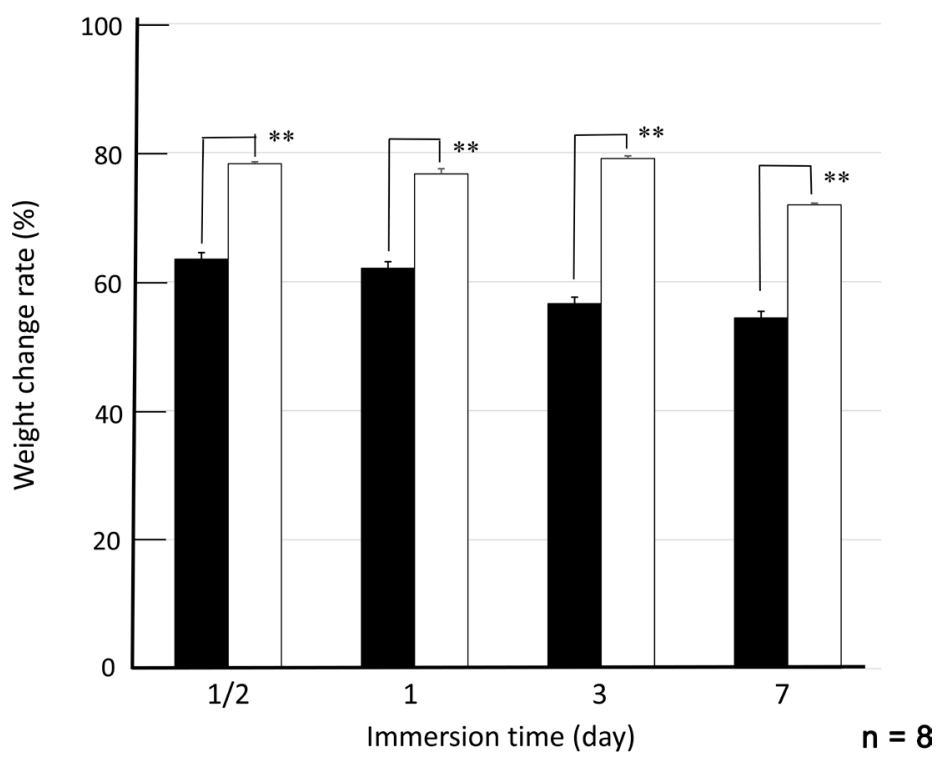

${ }^{*} \mathrm{P}<0.01$ vs. Sponge-A-15 [Student's t-test].

Figure 3. Weight change of Sponge-A-15 and Sponge-B-15 after immersion in water:

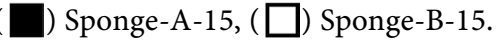

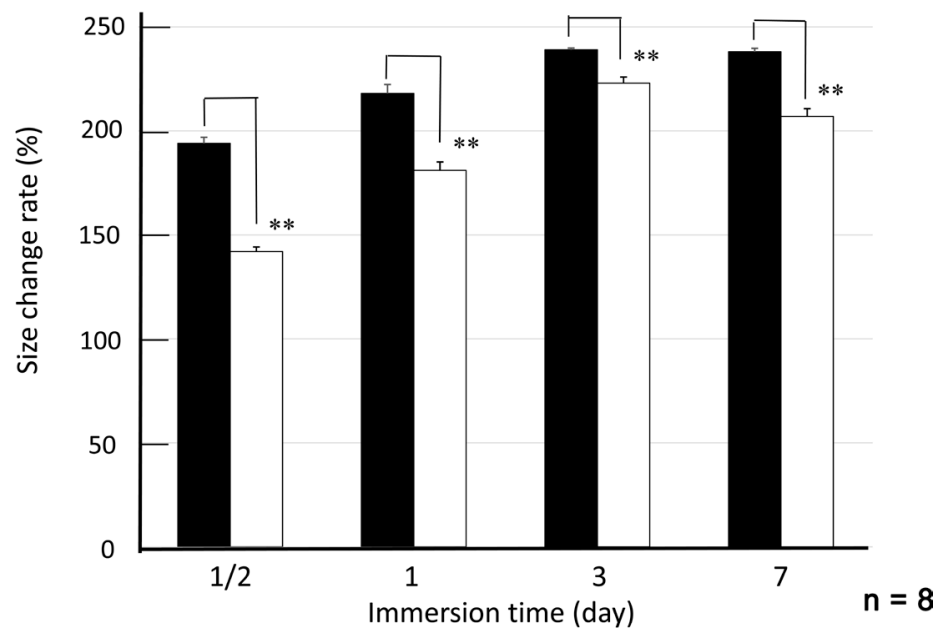

${ }^{* *} \mathrm{P}<0.01$ vs. Sponge- $\mathrm{A}-5$ [Student's t-test]

Figure 4. Size change of Sponge-A-5 and Sponge-B-5 after immersion in water: Sponge-A-5, ( $\square$ ) Sponge-B-5. 
was $199 \%, 218 \%, 245 \%, 233 \%$ of the original size, respectively. The size of sponge-B-10 was $145 \%, 133 \%, 174 \%, 197 \%$ of the original size, respectively (Figure 5). The size of sponge-A-15 was $170 \%, 176 \%, 208 \%, 221 \%$ of the original size, respectively. The size of Sponge-B-15 was $128 \%, 147 \%, 142 \%, 146 \%$ of the original size, respectively (Figure 6). There is no statistical difference among four data, 128\%, 147\%, 142\%, and 146\%. The findings shown in Figure 6 indicate that Sponge-B-15 having the highest intermolecular crosslinks rate can control the increase in size within about $150 \%$ of the original size for 7 days immersion in water.

\subsection{Enzymatic Degradation Rate of Spongy Sheet by Collagenase}

Under the condition of $0.0005 \%$ collagenase concentration, the weight of

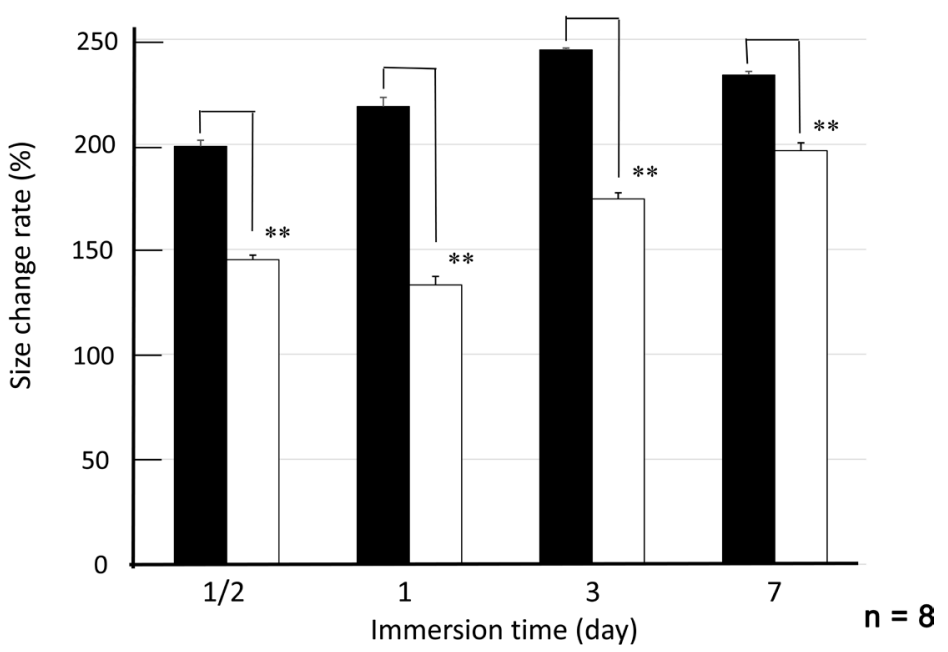

${ }^{* * \mathrm{P}}<0.01$ vs. Sponge-A-10 [Student's t-test]

Figure 5. Size change of Sponge-A-10 and Sponge-B-10 after immersion in water: Sponge-A-10, ( $\square$ ) Sponge-B-10.

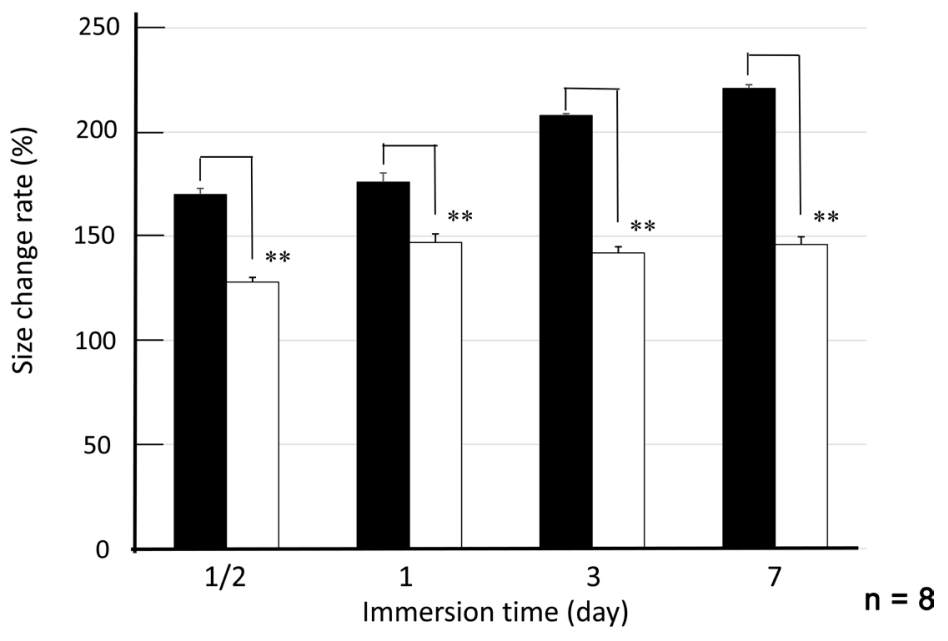

${ }^{* *} \mathrm{P}<0.01$ vs. Sponge-A-15 [Student's t-test]

Figure 6. Size change of Sponge-A-15 and Sponge-B-15 after immersion in water: Sponge-A-15, ( $\square$ ) Sponge-B-15. 
Sponge-A-15 collected 6, 8, 10, 12 hours after immersion in water was $65.7 \%$, $59.8 \%, 57.9 \%, 55.2 \%$ of the original weight, respectively. Spongy sheets failed to collect after 24 hours because of enzymatic degradation. Under the condition of $0.001 \%$ collagenase concentration, the weight of Sponge-A-15 collected after 6 and 8 hours after immersion in water was 57.6 and 40.7 of the original weight, respectively (Figure 7). Spongy sheet failed to collect after 10 hours because of enzymatic degradation.

Under the condition of $0.0005 \%$ collagenase concentration, the weight of Sponge-B-15 collected 6, 8, 10, 12 hours after immersion in water was 63.5, 52.1, $42.0,43.2 \%$ of the original weight, respectively. Spongy sheets failed to collect after 24 hours because of enzymatic degradation.

Under the condition of $0.001 \%$ collagenase concentration, the weight of Sponge-B-15 collected after 6, 8, 10 hours after immersion in water was $55.1 \%$, $45.1 \%, 26.1 \%$ of the original weight, respectively (Figure 8). Spongy sheets failed to collect after 12 hours because of enzymatic degradation.

\section{Discussion}

There are two important issues in the manufacturing process of the spongy sheet composed of HA and Col. The first issue in the manufacturing process is how to mix HA and Col to prepare a clear aqueous solution under neutral conditions. Col aqueous solution can be prepared under acidic conditions below $\mathrm{pH} 3$. When changed to the neutral region, Col molecules with a triple helical structure aggregate and partially precipitate. This phenomenon is considered as follows. Col molecule side chains change from charged state to neutral state. As a result, Col molecule side chains weaken bonding to surrounding water molecules.

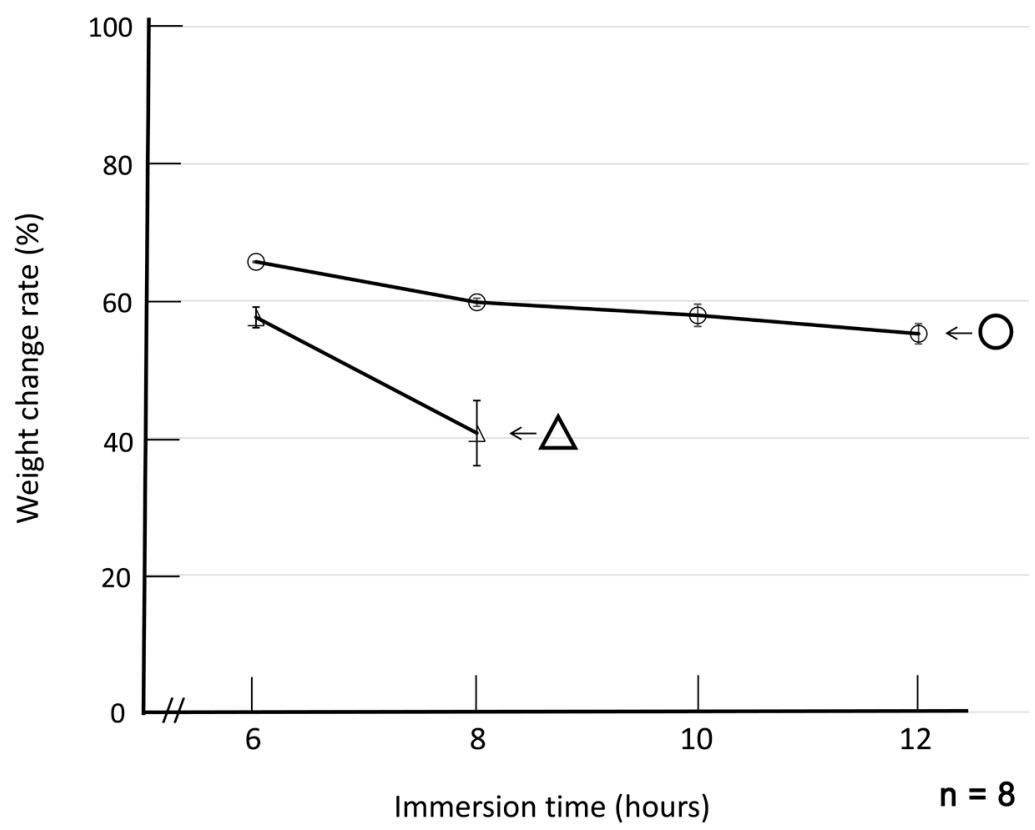

Figure 7. Enzymatic degradation rate of Sponge-A-15 after immersion in water containing collagenase: $(\bigcirc)$ 0.0005\% collagenase, $(\triangle) 0.001 \%$ collagenase. 


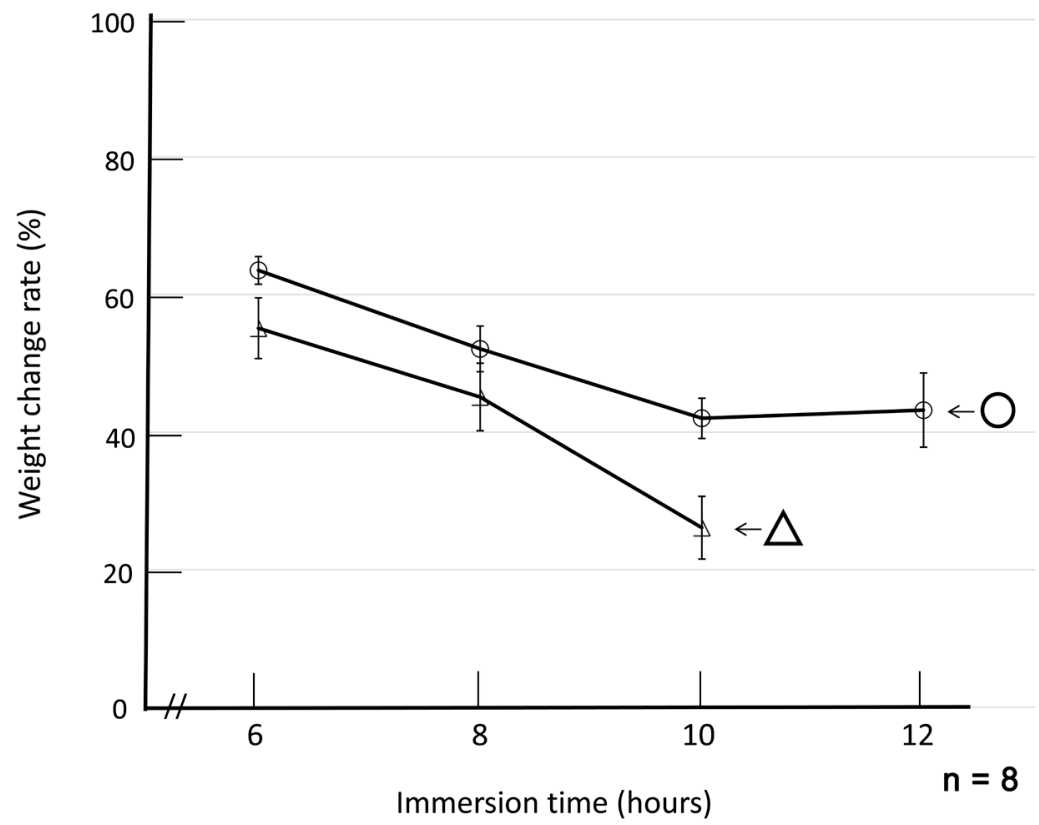

Figure 8. Enzymatic degradation rate of Sponge-B-15 after immersion in water containing collagenase: $(\bigcirc)$ 0.0005\% collagenase, $(\triangle) 0.001 \%$ collagenase.

These conditions facilitate side-by-side arrangement of Col molecules having a triple heliacal structure like a rod-like structure, thereby causing aggregation and precipitation. When Col aqueous solution is warmed above $40^{\circ} \mathrm{C}$, Col molecules undergo a conformational change from triple helical structure to random coil structure. This phenomenon reflects a decrease in viscosity. The results in this study demonstrated that the viscosity was $19.3,17.2,13.3,4.2$, less than $0.1 \mathrm{dPa} \cdot \mathrm{s}$ at $20^{\circ} \mathrm{C}, 25^{\circ} \mathrm{C}, 30^{\circ} \mathrm{C}, 35^{\circ} \mathrm{C}, 40^{\circ} \mathrm{C}$, respectively. Once $\mathrm{Col}$ aqueous solution is warmed at $60^{\circ} \mathrm{C}$, and then cooled to $20^{\circ} \mathrm{C}$, the viscosity at $20^{\circ} \mathrm{C}$ showed $0.4 \mathrm{dPa} \cdot \mathrm{s}$. This finding indicates that a random coil structure does not return to its original helical structure. The random coil structure inhibits side-by-side arrangement of Col molecules due to mutual steric hindrance. As a result, this heat-denatured Col aqueous solution can be kept transparent without causing any precipitation even under neutral conditions. Consequently, this heat-denatured Col aqueous solution can be mixed with HA aqueous solution under neutral conditions without causing any precipitation. This property of Col molecule is advantageous in manufacturing medical devices composed of $\mathrm{HA}$ and Col.

The second important issue in the manufacturing process is how to control the intermolecular crosslinks of spongy sheet. A spongy sheet composed of HA and $\mathrm{Col}$ is dissolve in water. In practical use, intermolecular crosslinks are required to control its water solubility. The general method for introducing intermolecular crosslinks is to use chemical cross-linking reagents having epoxy group such as ethylene glycol diglycidyl ether. This method needs to remove unreacted chemical cross-linking reagents after manufacturing a spongy sheet by freeze vacuum drying process. After rinsing a spongy sheet by immersion in water, the hydrated spongy sheet needs a second freeze vacuum drying process. 
This second process is disadvantageous in mass production. To overcome such disadvantages, this study adopted a method that does not use chemical cross-linking reagents. It is well known that intermolecular crosslinks between Col molecules is introduced by UV irradiation. This method is very useful in mass production. In this case, the second freeze vacuum drying process described above can be omitted. The results in this study demonstrate that heatdenatured Col molecules with random coil structure can be also cross-linked by UV irradiation. This property of Col molecule is also advantageous in manufacturing medical devices composed of HA and Col.

The manufactured spongy sheet is considered to have the unique structure, where HA molecules are entrapped in an intermolecular cross-linked network structure of Col molecules. When immersed in water, HA molecules are able to extract gradually from the Col network structure. When immersed in water containing collagenase, the weight loss of spongy sheet is accelerated by easy extraction of HA molecules from the enzymatic degraded Col network structure. In practice, the weight of Sponge-B-15 collected $1 / 2$ and 1 day after immersion in water was $78.3 \%$ and $76.7 \%$ of the original weight, respectively. On the other hand, the weight of Sponge-B-15 collected 1/2 day after immersion in water containing $0.0005 \%$ collagenase was $43.2 \%$ of the original weight. This spongy sheet failed to collect 1 day after immersion, because of enzymatic degradation. These results indicate that the intermolecular cross-linked Col network structure is decomposed by collagenase within 1 day, thereby the extraction of HA molecules is facilitated. In other words, these findings suggest the unique structure, where HA molecules are entrapped in an intermolecular cross-linked network structure of Col molecules.

The Co content in Sponge-A and Sponge-B is $16.7 \%$ and $50.0 \%$, respectively. The intermolecular crosslinks rate in Sponge-A-5 is lower than that in Sponge-B-15, because the crosslinks rate depends on Col content and UV irradiation time. When immersed in water, Sponge-A-5 has reduced weight and increased size compared to Sponge-B-15. In practice, the weight change of Sponge-A-5 and Sponge-B-15 collected 1 day after immersion in water was $56.2 \%$ and $76.7 \%$ of the original weight. The size of Sponge-A-5 and Sponge-B-15 collected 1 day after immersion in water was $218 \%$ and $147 \%$ of the original size. When intermolecular crosslinks rate is low, HA molecules extract easily form the Col network structure, thereby causes weight loss. In addition, the Col network structure becomes loose and causes an increase in size (Figure 9). The results demonstrated that the size of Sponge-A-15 and Sponge-B-15 collected 1 day after immersion in water was $176 \%$ and $147 \%$ of the original size. These findings also suggest the unique structure, where HA molecules are entrapped in an intermolecular cross-linked network structure of Col molecules (Figure 10).

The wound dressings need to facilitate the healing process under the impaired conditions such as burn injury and intractable skin ulcer. Spongy sheet needs to provide the scaffold for new tissue formation. Therefore, the spongy sheet with 


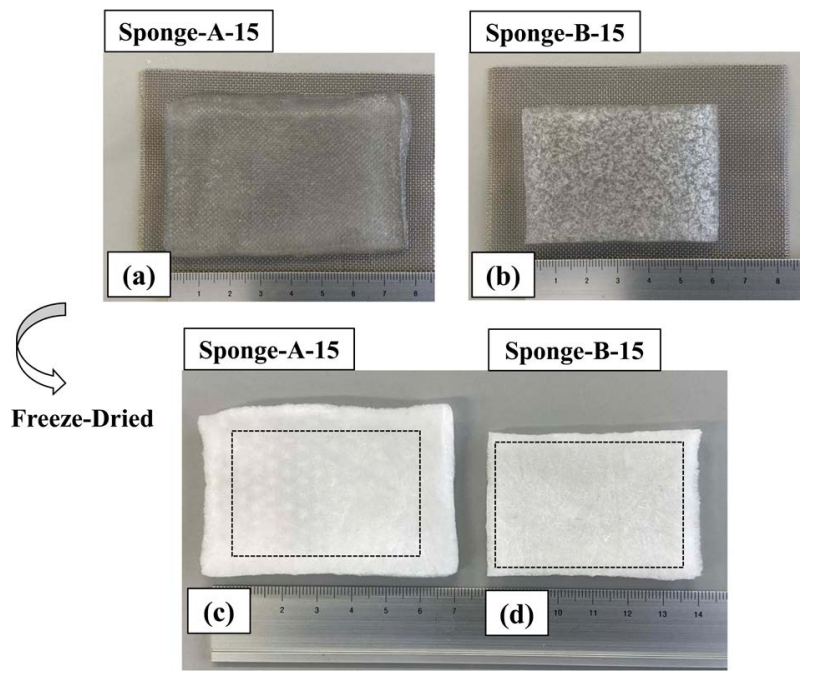

Figure 9. Spongy sheet collected 1 day after immersion in water: (a) Hydrated Sponge-A-15, (b) Hydrated Sponge-B-15, (c) Freeze vacuum dried Sponge-A-15, (d) Freeze vacuum dried Sponge-B-15, Dotted square; Original size of spongy sheet before immersion in water $(3.5 \mathrm{~cm} \times 5.5 \mathrm{~cm})$.

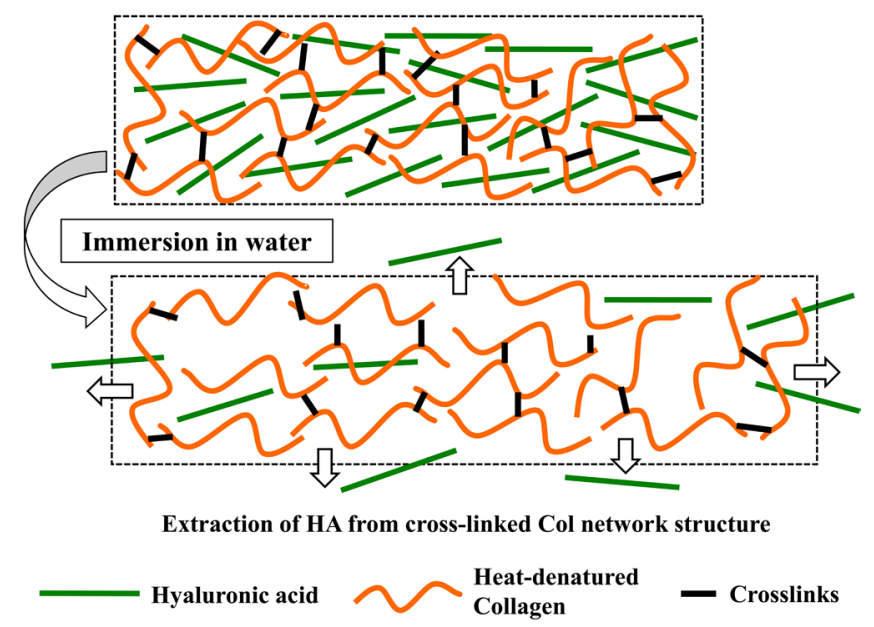

Figure 10. Molecular structure model of spongy sheet: HA molecules are entrapped in intermolecular cross-linked Col network structure. HA extract from the Col network structure, and thereby causing weight loss. In addition, the Col network structure becomes loose and causes an increase in size.

high Col ratio and high intermolecular crosslinks rate like Sponge-B-15 is expected to show excellent performance as wound dressings. In case of tissue anti-adhesive products, two events need to proceed simultaneously. One is to promote wound healing of surgically resected tissue surface. Another is to prevent surgically resected tissue surface from adhering to the surrounding tissue surface. The surgically resected tissue surface proceeds under normal wound healing process. The main performance of tissue anti-adhesive products is to prevent surgically resected tissue surface from adhering to the surrounding tissue surface. Therefore, the spongy sheet with low Col ratio and low intermolecular crosslinks rate like Sponge-A-5 is expected to show excellent performance 
as tissue anti-adhesive products, because easy extraction of HA molecules provides an environment to prevent tissue adhesion. In addition, the highly hydrated, enlarged spongy sheet caused by extraction of HA molecules is expected to provide an advantageous environment to prevent tissue adhesion.

Further development of this research is to explore a wide range of potential application of cell growth factors using the spongy sheet of HA and Col. In our previous study, wound dressings composed of $\mathrm{HA}$ and Col containing epidermal growth factor (EGF) were developed [8] [9]. It is well known that EGF is a potent stimulator of cell proliferation of various cells including keratinocytes, fibroblasts, and vascular endothelial cells [12] [13] [14]. This wound dressing was manufactured by freeze vacuum drying aqueous solution of HA and Col containing EGF to manufacture a spongy sheet, followed by UV irradiation to introduce crosslinks between Col molecules. The efficacy of this wound dressing was investigated in clinical trials. Most clinical cases were assessed as having achieved good or excellent results [10]. The manufacturing process of this wound dressing is very practical. However, the activity of EGF is expected to reduce to some extent by UV irradiation. When use other unstable cell growth factors, the reduction of activity by UV irradiation is a problem to be solved. The best way to overcome such problems is to laminate two different spongy sheets. The first spongy sheet is manufactured by freeze vacuum drying an aqueous solution of HA and Col, and followed by UV irradiation to introduce intermolecular crosslinks between Col molecules. The second spongy sheet is manufactured by freeze vacuum drying an aqueous solution of HA containing cell growth factor such as basic fibroblast growth factor, vascular endothelial growth factor or hepatocyte growth factor. These cell growth factors are known to be the most potent cytokines for the promotion of wound angiogenesis [15] [16] [17] [18]. The first cross-linked spongy sheet on top and the second non-cross-linked spongy sheet containing cell growth factor on bottom are laminated to prepare a two-layered spongy wound dressing (Figure 11). Both spongy sheets can be

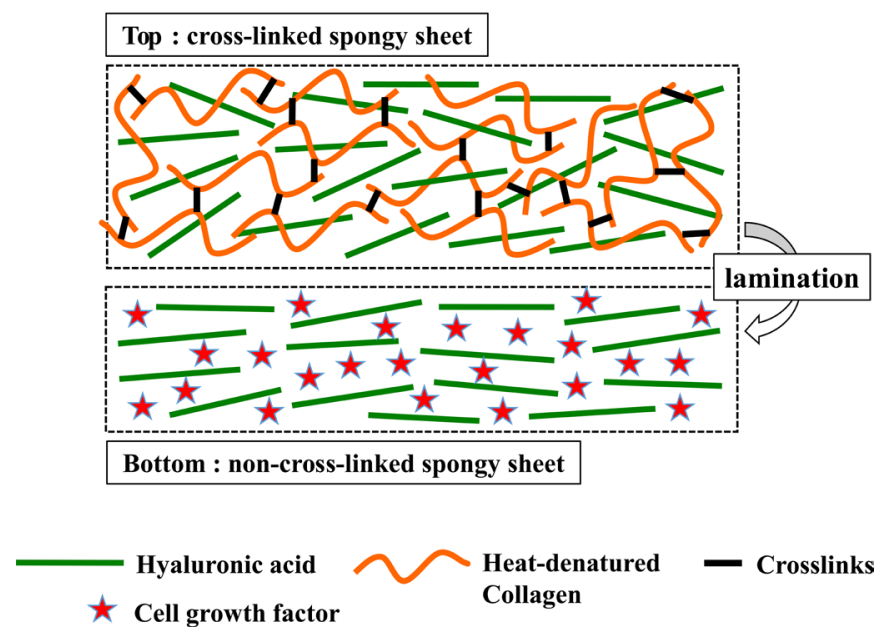

Figure 11. Two-layered molecular structure model: cross-linked spongy sheet on top and non-cross-linked spongy sheet containing cell growth factor on bottom. 
laminated with only slight pressure, because the surface of both spongy sheets has porous structure with soft physical properties. In particular, non-crosslinked spongy sheet of HA containing cell growth factor has very soft physical properties [19] [20].

\section{Conclusion}

The spongy sheet with high Col ratio and high intermolecular crosslinks rate is expected to show excellent performance as wound dressings, because the Col network structure provides an environment to facilitate new tissue formation. On the other hand, the spongy sheet with low Col ratio and low intermolecular crosslinks rate is expected to show excellent performance as tissue anti-adhesive products, because easy extraction of HA molecules provides an environment to prevent adhesion between tissues.

\section{References}

[1] Kuroyanagi, Y. (2016) Tissue-Engineered Product for Skin Regenerative Medicine. Open Journal of Regenerative Medicine, 5, 61-84. https://doi.org/10.4236/ojrm.2016.53006

[2] Kuroyanagi, M. and Kuroyanagi, Y. (2017) Tissue-Engineered Products Capable of Enhancing Wound Healing. AIMS Materials Science, 4, 561-581. https://doi.org/10.3934/matersci.2017.3.561

[3] Kuroyanagi, M. and Kuroyanagi, Y. (2018) Advanced Treatment of Burns and Skin Ulcers Using Tissue-Engineered Products. Dermatology Case Reports, 3, 137-142. https://doi.org/10.35248/2684-124X.18.3.137

[4] Kuroyanagi, M. and Kuroyanagi, Y. (2018) Design Concept of Tissue-Engineered Products for Use in Emergency and Critical Care Medicine. Biomedical Journal of Science \& Technology Research, 2, 692-694. https://doi.org/10.26717/BJSTR.2018.02.000692

[5] John Chen, W.Y. and Abatangelo, G. (1999) Functions of Hyaluronan in Wound Repair. Wound Repair and Regeneration, 7, 79-89. https://doi.org/10.1046/j.1524-475X.1999.00079.x

[6] Pardue, E.L., Ibrahim, S. and Ramamurthi, A. (2008) Role of Hyaluronan in Angiogenesis and Its Utility to Angiogenic Tissue Engineering. Organogenesis, 4, 203-214. https://doi.org/10.4161/org.4.4.6926

[7] Postlethwaite, A.E., Seyer, J.M. and Kang, A.H. (1978) Chemotactic Attraction of Human Fibroblasts to Type I, II, and III Collagens and Collagen-Derived Peptides. Proceedings of the National Academy of the Sciences of the United States of America, 78, 871-875. https://doi.org/10.1073/pnas.75.2.871

[8] Kondo, S. and Kuroyanagi, Y. (2011) Development of a Wound Dressing Composed of Hyaluronic Acid and Collagen Sponge with Epidermal Growth Factor. Journal of Biomaterials Science, Polymer Edition, 23, 629-643. https://doi.org/10.1163/092050611X555687

[9] Kondo, S., Niiyama, H., Yu, A. and Kuroyanagi, Y. (2012) Evaluation of a Wound Dressing Composed of Hyaluronic Acid and Collagen Sponge Containing Epidermal Growth Factor in Diabetic Mice. Journal of Biomaterials Science. Polymer Edition, 23, 1729-1740. https://doi.org/10.1163/092050611X597799

[10] Yu, A., Takeda, A., Kumazawa, K., Miyoshi, H., Kuroyanagi, M., Yoshitake, T., 
Uchinuma, E., Suzuki, R. and Kuroyanagi, Y. (2015) Preliminary Clinical Study Using a Novel Wound Dressing Composed of Hyaluronic Acid and Collagen Containing EGF. Open Journal Regenerative Medicine, 4, 6-13. https://doi.org/10.4236/ojrm.2015.41002

[11] Kuroyanagi, M., Yamamoto, A., Shimizu, N., Toi, A., Inomata, T., Takeda, A. and Kuroyanagi, Y. (2014) Development of Anti-Adhesive Spongy Sheet Composed of Hyaluronic Acid and Collagen Containing Epidermal Growth Factor. Journal of Biomaterials Science, Polymer Edition, 25, 1253-1265.

https://doi.org/10.1080/09205063.2014.926579

[12] Carpenter, G. and Cohen, S. (1976) Human Epidermal Growth Factor and the Proliferation of Human Fibroblasts. Journal of Cell Physiology, 88, 227-237. https://doi.org/10.1002/jcp.1040880212

[13] Carpenter, G. and Cohen, S. (1979) Epidermal Growth Factor. Annual Review of Biochemistry, 48, 193-216. https://doi.org/10.1146/annurev.bi.48.070179.001205

[14] Buckley, A., Davidson, J.M., Kamerath, C.D., Wolt, T.B. and Woodward, S.C. (1985) Sustained Release of Epidermal Growth Factor Accelerates Wound Repair. Proceedings of the National Academy of Sciences of the United States of America, 82, 7340-7344. https://doi.org/10.1073/pnas.82.21.7340

[15] Yu, A., Matsuda, Y., Takeda, A., Uchinuma, E. and Kuroyanagi, Y. (2012) Effect of EGF and bFGF on Fibroblast Proliferation and Angiogenic Cytokine Production from Cultured Dermal Substitutes. Journal of Biomaterials Science, Polymer Edition, 23, 1315-1324. https://doi.org/10.1163/092050611X580463

[16] Bros, P. and Miller, C.M. (1995) Hepatocyte Growth Factor: A Multifunctional Cytokine. The Lancet, 345, 293-295. https://doi.org/10.1016/S0140-6736(95)90279-1

[17] Toyoda, M., Takayama, H., Horiguchi, N., Otsuka, T., Fulusato, T., Merlino, G., Takagi, H. and Mori, M. (2001) Overexpression of Hepatocyte Growth Factor/Scatter Factor Promotes Vascularization and Granulation Tissue Formation in Vivo. FEBS Letters, 509, 95-100. https://doi.org/10.1016/S0014-5793(01)03126-X

[18] Xin, X., Yang, S., Ingle, G., Zlot, C., Rangell, L., Kowalski, J., Schwall, R., Ferrara, N. and Gerritsen, M.E. (2001) Hepatocyte Growth Factor Enhances Vascular Endothelial Growth Factor-Induce Angiogenesis in Vitro and in Vivo. The American Journal of Pathology, 158, 1111-1120. https://doi.org/10.1016/S0002-9440(10)64058-8

[19] Isago, Y., Suzuki, R., Isono, E., Noguchi, Y. and Kuroyanagi, Y. (2014) Development of a Freeze-Dried Skin Care Product Composed of Hyaluronic Acid and Poly $(\gamma$-Glutamic Acid) Containing Bioactive Components for Application after Chemical Peels. Open Journal of Regenerative Medicine, 3, 43-53. https://doi.org/10.4236/ojrm.2014.33006

[20] Yamamoto, A., Ohno, H. and Kuroyanagi, Y. (2016) Evaluation of Epidermal Growth Factor-Incorporating Skin Care Product in Culture Experiment Using Human Fibroblasts. Open Journal of Regenerative Medicine, 5, 44-54.

https://doi.org/10.4236/ojrm.2016.52004 